\title{
Some observations on memory impairment after temporal lobectomy for epilepsy
}

\author{
EUSTACE A. SERAFETINIDES AND MURRAY A. FALCONER
}

\author{
From the Guy's-Maudsley Neurosurgical Unit, London
}

Impairment of memory, and particularly of recent memory, following lesions of the temporal lobe has been reported by several authors in the past decade. Thus Penfield and Milner (1958) described three instances of recent memory disturbance after unilateral temporal lobectomy, and pointed out that in these particular patients there were post-operatively E.E.G. abnormalities in the opposite temporal lobe. Walker (1957) also noted four instances of memory impairment after unilateral temporal lobectomy. Other authors, to whom we shall refer, have recorded this same phenomenon in necropsy and clinical studies, where there were definite structural abnormalities in the mesial portions of the temporal lobes, particularly of the hippocampus.

We have therefore attempted in those of our patients submitted to a unilateral temporal lobectomy for epilepsy to ascertain how frequently memory is impaired, and when it is if it is possible to correlate this phenomenon with evidence of bilateral temporal lobe disturbances, As this study has of necessity been based on patients who are still surviving and pathological studies of the opposite temporal lobe consequently are not available, we have accepted as a criterion for a bilateral temporal lobe disturbance that there should be a focus of abnormal electrical activity in the temporal lobe contralateral to that which was removed. We have further confined ourselves to cases of lobectomy of the right and non-dominant cerebral hemisphere, both for the sake of homogeneity and because our colleagues (Meyer and Yates, 1955; Meyer, 1959) have shown that impairment of auditory learning can follow removal of the dominant temporal lobe but not of the minor lobe alone.

\section{CASE MATERIAL}

Thirty-four consecutive patients with an ablation of the right anterior temporal lobe were studied. All had been operated on for epilepsy according to criteria given elsewhere (Falconer, Hill, Meyer, Mitchell, and Pond, 1955) and subsequently all had been personally followed up for periods ranging from one complete year to nine years. Information was available not only about each patient's clinical progress as regards epilepsy and behaviour, but also about the pathological changes in the resected specimen, as well as one or more sphenoidal E.E.G. studies performed with the patient under pentothal at intervals of from one to five years after operation. The follow-up studies usually included an assessment from a close relation or friend. A clinical assessment of recent memory impairment was also available, based either on the patient's spontaneous complaints, or on answers to leading questions which were then substantiated by observations of a relative or by the clinician's own observations. The assessment was never made on leading questions alone. Similarly each patient's memory had been assessed pre-operatively. Standard intelligence test scores were available for most patients before and after operation.

\section{ILLUSTRATIVE CASES}

In order to clarify the type of disability with which we are concerned two case histories will be given, one illustrating a slight and transient defect of recent memory and the other a more severe and persistent defect. In no instance in our series, however, did these defects incapacitate the patients, for they could usually compensate for them.

CASE 1 FIT ${ }^{1}$, a 40-year-old man referred by Dr. E. Clarke, had suffered from epileptic attacks since he was 28 years old. His birth was premature, but otherwise his medical history seemed irrelevant until the age of 25 years when he had malaria with delirium. His epileptic attacks ranged in severity from psychomotor to grand mal but in neither type was there any remembered aura. The minor attacks were characterized by sucking movements and incoherent speech, and occurred about once every two days in spite of medication. The major attacks occurred once a month. He was an anxious, worrying individual but without any major psychiatric symptoms. The neurological examination, skull radiographs, and air encephalograms were all normal, but several routine

${ }^{1}$ It has been the practice of our colleagues in reporting various aspects of our operated cases to identify individual patients by the first three letters of the surnames. 
and pentothal sphenoidal E.E.G.s showed widespread spike-and-sharp-wave discharges over the right temporal areas, both at the sphenoidal electrode and over the convexity. There were no discharges on the left. A $6 \cdot 5 \mathrm{~cm}$. right anterior temporal lobectomy was performed, the resected specimen showing non-specific gliotic changes (Dr. J. B. Cavanagh). Four years later the patient reported that he was free of fits, and that with the exception of a few periods of transient depression he generally felt well. He was working satisfactorily as a production planner in a factory. During the first postoperative year, however, he had complained of a bad memory for recent events. As instances of this he said that he was apt to forget names and figures in connexion with his work, and as a consequence had taken to making written lists and meticulous diaries, which he regularly consulted. Earlier in the year he had been depressed, but at the time of his memory complaint depression was not evident. It is interesting that at this time the E.E.G. showed some spikes at the contralateral sphenoidal electrode. During the second and third years he had further bouts of depression, but his memory for recent details was intact and his E.E.G. was normal. After the third year he exhibited all-round improvement.

CASE 2 GRE, a 35-year-old housewife, referred by Dr. W. B. Matthews, had developed epileptic attacks at the age of 27 years in spite of a negative family history, normal birth, and normal childhood. Her attacks were both nocturnal and diurnal. In the nocturnal attacks she would suddenly cry out, stare ahead, and rub her abdomen. Next she would develop clonic movements of all four limbs. These nocturnal attacks lasted on average three to four minutes. In the diurnal attacks, which lasted up to 30 seconds, she would stare ahead, and make mouthing movements, then sometimes fall to the floor motionless. Subsequently she would recall a visual aura of a man's face inside her own head. She averaged two to four attacks per day. Following the onset of these attacks her personality changed, becoming anxious and at times depressed. No abnormal physical signs were found and her I.Q. was 108 (Wechsler-Bellevue) without any discrepancies between performance and verbal scales. The E.E.G. studies showed an active spike-discharging focus at the right sphenoidal electrode with only an occasional discharge at the left sphenoidal electrode. A $6.5 \mathrm{~cm}$. right anterior temporal lobectomy was performed with subsequent pathological findings of a non-specific gliosis of white matter (Dr. J. B. Cavanagh). The fits, however, persisted with little change and her personality was not altered. Three and a half years later an E.E.G. showed frequent discharges at the contralateral sphenoidal electrode. Her husband said that she was still as efficient in managing her housework as before but that now when she went shopping she was forgetful. He further instanced that on her last follow-up visit she did not seem to recall the dates of her previous visits or the layout of the hospital. Yet she was correctly orientated as to the day, lucid in her replies, and knew the name of the hospital. Later she was observed to find her way correctly through a complicated corridor. The patient herself said that not infrequently she forgot some of the items she had set out to buy on her shopping expeditions and that she had difficulty in remembering people's faces and names. Also that when shopping she always paid for the goods with a pound note and hoped for the correct change, as she could not remember shopping prices. She could not recall the date of her operation or the name of the doctor who had last seen her. It is interesting that in her case there had been a complaint of impairment of recent memory before operation, and this was now worse.

\section{ANALYSIS OF CASE MATERIAL}

Our 34 patients were subdivided into three groups according to their last post-operative E.E.G. which, in all instances, was one year after operation and mostly over three years. The distribution was as follows:-

Group A comprised 17 cases with normal E.E.G. findings.

Group B comprised 10 cases with non-specific convexity E.E.G. abnormalities ${ }^{1}$ either unilateral or bilateral, but without a contralateral sphenoidal focus.

Group C comprised seven cases with spike discharges at the contralateral sphenoidal electrode, with or without an ipsilateral sphenoidal abnormality. It was in this group that we found most of the cases with persistently impaired recent memory.

The salient clinical features of the 34 cases are given in Tables I and II. In the 17 cases in group A the epilepsy usually started in the first decade, and operation was usually performed in the second decade. Only two patients developed impairment of recent memory post-operatively, although three others showed it before operation; impairment was either slight or transient. The underlying pathology in half the cases was sclerosis of the hippocampus and adjacent structures (e.g., uncus, amygdala) and in the other half small focal lesions of various types (Falconer and Cavanagh, 1959). All patients but one were improved as regards epilepsy. Many patients were followed up for four years or longer.

The patients in group B had many similarities with those of group $A$, particularly in terms of paucity of persistent memory impairment and a conspicuous number of small focal lesions. The age of onset of epilepsy tended to be a decade later, as did the age at operation. In the follow-up only one patient was free of fits but the others were all greatly benefited. Nearly all the patients were followed-up for more than four years.

Group C differs strikingly from the other two groups in that six of the seven patients had persistent impairment of memory. A pre-operative impairment

${ }^{1}$ The non-specific convexity abnormalities (Driver and Serafetinides, 1960) comprise slow waves between 2 and $6 \mathrm{c} / \mathrm{s}$ of high amplitude tending to increase on overbreathing as well as ipsilateral slowing of the alpha rhythm. 
TABLE I

CLINICAL FEATURES

Clinical and Pathological Data

Group A (Cases with Normal E.E.G.)

Group B (Cases with

Group C (Cases with Non-specific Changes)

Contralateral Sphenoidal Focus)

Age of onset of epilepsy (total cases)
Before 10 years
11 to 30 years
Over 31 years
Age at operation
Before 20 years
21 to 40 years
Over 41 years
After operation
No memory impairment
Slight and/or transient impairment
Persistent impairment

Sclerosis of hippocampus and other mesial structures Non-specific gliosis

Other lesions, tumours, scars

mesial structures

$\begin{array}{ccc}17 & 10 & 7 \\ 9 & 4 & 4 \\ 5 & 4 & 3 \\ 3 & 2 & 0 \\ & & \\ 8 & 3 & 1 \\ 6 & 6 & 4 \\ 3 & 1 & 2 \\ & & \\ 12 & 7 & 1 \\ 5 \text { (pre-operative in 3) } & 7 \text { (pre-operative in 2) } & 0 \\ 0 & 1 & 6 \text { (pre-operative in 4) } \\ 8 & 2 & 4 \\ 1 & 2 & 3 \\ 8 & 6 & 0\end{array}$

TABLE II

FOLLOW-UP DATA

\begin{tabular}{|c|c|c|c|}
\hline Follow-up Data & $\begin{array}{l}\text { Group A (Cases with } \\
\text { Normal E.E.G.s) }\end{array}$ & $\begin{array}{l}\text { Group B (Cases with } \\
\text { Non-specific Changes) }\end{array}$ & $\begin{array}{l}\text { Group C (Cases with Contra- } \\
\text { latera! Sphenoidal Focus) }\end{array}$ \\
\hline \multicolumn{4}{|l|}{ Fit pattern } \\
\hline Psychomotor & 10 & 5 & 4 \\
\hline Psychomotor plus grand mal & 7 & 5 & 3 \\
\hline \multicolumn{4}{|l|}{ Fit outcome } \\
\hline Fit-free & 9 & 1 & $\mathbf{0}$ \\
\hline Occasional fits & 7 & 9 & 1 \\
\hline Persisting fits & 1 & 0 & 6 \\
\hline Worse & 0 & 0 & $\mathbf{0}$ \\
\hline \multicolumn{4}{|l|}{ Psychiatric pattern ${ }^{1}$} \\
\hline Neurosis & 7 & 4 & 2 \\
\hline Personality disorders & 3 & 3 & 4 \\
\hline Paroxysmal mood changes & 4 & 4 & 4 \\
\hline Psychosis & 2 & 0 & 1 \\
\hline Normal & 2 & 0 & 0 \\
\hline Improved & 7 & 2 & 4 \\
\hline Unchanged & 10 & 8 & 3 \\
\hline Worse & 0 & 0 & 0 \\
\hline \multicolumn{4}{|l|}{ Duration of follow-up } \\
\hline 1 year & 2 & 0 & $\mathbf{0}$ \\
\hline 2 to 3 years & 7 & 1 & 1 \\
\hline 4 to 5 years & 3 & 3 & 2 \\
\hline Ovet 5 years & 5 & 6 & 4 \\
\hline
\end{tabular}

'Some patients had more than one pattern

in four of these had been worsened. It is interesting that there was no instance of a small focal lesion, four of the patients having hippocampal sclerosis and three non-specific gliotic changes. The age of onset of epilepsy again tends to be a little older than group A, while the age of operation was usually after the second decade. Six out of the seven patients still had frequent fits, including five with a new type, e.g., convulsive seizures without an aura. The followup was again usually more than four years. Thus while in groups A and B only one out of 27 patients developed a persistent memory deficit, six out of seven cases of group $C$ showed this defect. In seven other cases of groups A and B a slight but transient defect was observed.

\section{CORRELATION OF MEMORY IMPAIRMENT WITH PSYCHOLOGICAL TESTS}

This is of course a retrospective study based upon observations made from one to nine years after operation. The assessment of recent memory impair- 
ment is a clinical one, and we tried to see whether or not clinical impressions could be correlated with similar changes in the routine psychological tests. We therefore studied the six patients with persistent memory defects in group C. Four of these patients had been given the Wechsler-Bellevue intelligence test, including the Wechsler memory scale as well as the auditory learning test devised by Meyer (1959), both pre-operatively and one or more years postoperatively. In only one of these four patients did the Wechsler memory scale show a significant decline post-operatively but in this particular patient the auditory learning ability was intact. In another patient there was no impairment pre- and postoperatively on the Wechsler memory scale but Meyer's test showed some defect in the acquisitive phase of auditory learning. In the remaining two patients there was no impairment in either set of tests, and in none of the four patients was there any decline or discrepancy in the Wechsler-Bellevue test one year after operation. Psychological data are not available for the remaining two of the six patients. It seems therefore that the type of memory defect we are now considering does not correlate with the more formal psychological test results.

\section{DISCUSSION}

These findings thus support the hypothesis that the greatest incidence of impairment of recent memory after unilateral temporal lobectomy occurs in those cases which have persistent E.E.G. abnormalities in the mesial portion of the contralateral temporal lobe, as determined by sphenoidal electrode E.E.G. studies performed at least one year after operation. Conversely, cases without post-operative memory impairment usually have either normal postoperative E.E.G.s or abnormalities of an unspecific nature involving only the temporal lobe convexities, either unilaterally or bilaterally.

There is a strong presumption that spike or sharpwave discharges at the contralateral sphenoidal electrode indicate, if not a lesion, at least a dysfunction of the opposite temporal lobe. Therefore, in such postoperative cases after unilateral temporal lobectomy, we may consider that the functions of both temporal lobes are disturbed, particularly in their mesial portions. These assumptions are supported by the fact that post-operatively cases with persistent E.E.G. signs tend to show a higher proportion with continuing fits, and sometimes with fits of a new type.

These presumptions receive considerable support from the literature. Thus Grunthal (1947) found bilateral softenings of the hippocampi at necropsy in a patient with severe impairment of recent memory following prolonged insulin coma. Glees and Griffiths (1952) found bilateral cystic lesions in the hippocampi in a patient with prominent recent memory impairment. Recently Victor, Angevine, Mancall, and Fisher (1961) surveyed the literature and added a case of their own with bilateral infarctions in the hippocampal formation, fornix, and mammillary body secondary to arteriosclerotic occlusions of both posterior cerebral arteries. Their patient, in addition to impairment of recent memory, displayed an incomplete retrograde amnesia for the two years before the onset of his illness.

Surgical experience has been similar. Scoville and Milner (1957), for instance, reported that bilateral resection of the hippocampal structures performed for psychosis was followed by grave loss of recent memory, whereas bilateral removal of the uncal and amygdalar regions alone did not have this effect. Terzian (1958) in his review of the literature on bilateral temporal lobectomy stressed the associated profound impairment of memory.

Recently Stepien, Cordeau, and Rasmussen (1960) showed in African green monkeys that memory disturbances could follow bilateral temporal lobe ablations. If the resections involved the first and second temporal convolutions in front of the primary auditory area, auditory memory was impaired. If the resections involved the postero-inferior temporal cortex, visual memory was impaired. When the rhinencephalic portions (amygdala and hippocampus) were excised both types of memory were impaired.

All the above observations relate to loss of memory following destruction of the temporal lobes. It is interesting that electrical stimulation of the temporal lobe in conscious patients, either on its surface (Penfield, 1952) or in its depths (Bickford, Mulder, Dodge, Svien, and Rome, 1958; Penfield and Roberts, 1959), has occasionally evoked the reliving of past memories.

Similar studies to our own were those of Penfield and Milner (1958) who described some impairment of recent memory in three patients after removal of the dominant temporal lobe. All three patients showed E.E.G. abnormalities in the contralateral temporal lobe, and the authors inferred that their patients were deprived post-operatively of hippocampal functions. Walker (1957) has also reported similar observations in four patients, and moreover has stressed that impairment of recent memory occurs in 10 to $15 \%$ of patients after unilateral temporal lobectomy of either side, and may also be present before operation. However, he did not try to correlate his observations with E.E.G. evidence of bilateral temporal dysfunction.

Our own studies amplify those of Penfield and Milner in respect of the incidence of persistent 
impairment of recent memory in a consecutive group of 34 patients (seven cases or $21 \%$ ); the restriction of the study to ablations of the minor temporal lobe, thus avoiding the possibility that the phenomenon is due to impairment of auditory learning; the long E.E.G. and clinical follow-up periods; and the demonstration that persistent impairment of memory is absent when the post-operative E.E.G. is normal or shows only unspecific features.

Other subsidiary points to which attention should be drawn are that in patients with impairment of memory, both the age of onset and the age at which operation was carried out were appreciably older than in patients with normal memory. Indeed many of them showed a tendency to forgetfulness before operation which was subsequently aggravated. Of course there is the well-known fact that recent memory declines with age, but it is unlikely that this is the explanation considering the discussed factors of persisting epilepsy and contralateral E.E.G. abnormalities.

In our patients there was no instance of dysphasia or of an appreciable defect of auditory learning (Meyer, 1959). Defective reception of speech, therefore, could not be held responsible for the memory impairment, although in other circumstances of clinically bad memory it can be important.

This leads us finally to a critique of our study. First, as the assessment of impairment of memory was a clinical one, it would tend to underestimate both its frequency and its severity rather than the reverse. Secondly, we have not tried to make any finer distinction as to the degree and kind of memory impairment beyond the crude one of recent memory as opposed to remote and persistent impairment as opposed to transient. Ours has been a retrospective study, and any more detailed assessment would require a designed experiment. However, we feel that impairment of memory, as we have defined it, is a valid criterion, even although it cannot be quantified. In this respect it is at least as reliable as one of the most common symptoms in clinical medicine, viz., pain. Thirdly, we have presumed that a spikedischarging focus at the contralateral sphenoidal electrode indicates a dysfunction of that temporal lobe, although not necessarily a lesion. However, there is a considerable volume of clinical and experimental data to support such a claim.

\section{SUMMARY}

In a group of 34 patients in whom a temporal lobectomy was performed for epilepsy on the right and non-dominant hemisphere, recent memory was assessed. Thus the possibility of any post-operative dysphasia or auditory learning defect was avoided.
The assessment of impairment of memory was a purely clinical one.

In seven of the 34 patients evidence was present of some impairment persisting up to the last followup (two to nine years after operation) but in no instance was such impairment disabling. It was usually compensated for and was not revealed by formal psychometric tests.

In all patients sphenoidal E.E.G. studies had been made with the patient under pentothal both before operation and from one to five years afterwards. It was found that only one out of 27 patients with normal post-operative E.E.G.s or E.E.G. records with non-specific changes had developed a persistent memory defect. However, six of the seven patients who post-operatively had a spike-discharging focus at the sphenoidal electrode beneath the opposite (or unoperated) temporal lobe exhibited such a defect. Moreover, this latter group of patients had a higher incidence of persistent epilepsy (six cases out of seven) than did those with satisfactory post-operative E.E.G.s (one case out of 27).

It is argued that the presence of a spike-discharging focus at the opposite sphenoidal electrode indicates a dysfunction of that temporal lobe, if not a lesion. Therefore such cases can be considered as showing bilateral temporal lobe disturbances which are responsible for the memory defect.

We are very grateful to our many colleagues who have helped us in this study, particularly Professor Denis Hill, formerly of the Department of Clinical Neurophysiology at the Maudsley Hospital. We are particularly indebted to the Medical Research Council who have given financial support which has made possible this and other studies in connexion with the surgical relief of epilepsy.

\section{REFERENCES}

Bickford, R. G., Mulder, D. W., Dodge, H. W., Svien, H. J., and Rome, H. P. (1958). Res. Publ. Ass. nerv. ment. Dis., 36, 227.

Driver, M. V., and Serafetinides, E. A. (1960). Electrcenceph. clin. Neurophysiol., $12,758$.

Falconer, M. A., and Cavanagh, J. B. (1959). Brain, 82, 483.

, Hill, D., Meyer, A., Mitchell, W., and Pond, D. (1955). Lancet, 1,827 .

Glees, P., and Griffiths, H. B. (1952). Mschr. Psychiat. Neurol., 123, 193.

Grunthal, E. (1947). Ibid., 113, 1.

Meyer, V. (1959). A.M.A. Arch. Neurol. Psychiat., 81, 299.

and Yates, A. J. (1955). J. Neurol. Neurosurg. Psychiat., $18,44$.

Penfield, W. (1952). A.M.A. Arch. Revrol. Psychiat., 67, 178.

, and Milner, B. (1958). Ibid., 79, 475.

_-, and Roberts, L. (1959). Speech and Brain-Mechanisms. Princeton University Press, Princeton, N.J.

Scoville, W. B., and Milner, B. (1957). J. Neurol. Neurosurg. Psychiat,, 20, 11 .

Stepien, L. S., Cordeau, J. P., and Rasmussen, T. (1960). Brain, 83, 470.

Terzian, H. (1958). In Temporal Lobe Epilepsy, p. 510, ed. by M. Baldwin and $\mathbf{P}$. Bailey. Thomas, Springfield, Illinois.

Victor, M., Angevine, J. B., Mancall, E. L., and Fisher, C. M. (1961). Arch. Neurol. (Chicago), 5, 244.

Walker, A. E. (1957). A.M.A. Arch. Neurol. Psychiat., 78, 543. 